\title{
Kant, Kelsen, Carl Schmitt e a Teoria da Fundação Constitucional
}

\author{
Kant, Kelsen, Carl Schimitt and the \\ Constitutional Foundation Theory
}

(c)

João Carlos Brum Torres ${ }^{\left[\mathrm{[a]}[\mathrm{b}]^{*}\right.}$

[a] Universidade de Caxias do Sul, Caxias do Sul, RS, Brasil

[b] Universidade Federal do Rio Grande do Sul, Porto Alegre, RS, Brasil

\section{Resumo}

O presente artigo compara a perspectiva de Hans Kelsen e de Carl Schmitt, enquanto representantes de uma perspectiva normativista e decisionista da constituição, na sua abordagem da questão da fundação constitucional. Ao contrário de uma abordagem habitual, o presente artigo argumenta que é possível encontrar em Kant uma proximidade insuspeita com o decisionismo de Schmitt.

Palavras-chave: Constituição. Normativismo. Decisionismo. Kant. Kelsen.

* JCBT: Doutor; e-mail: brumtorres@gmail.com 


\section{Abstract}

The present paper compares Hans Kelsen's and Carl Schmitt's perspective, as representatives of a normativist and a decisionist perspective of the constitution, in their approach to the question of the constitutional foundation. Unlike the usual approach, the paper argues that it is possible to find in Kant an unsuspected closeness to Schmitt's decisionism.

Keywords: Constitution. Normativism. Decisionism. Kant. Kelsen.

I

Pode-se dizer que o principal problema filosófico colocado pela teoria geral do Estado e pelo direito público é a questão da fundação constitucional.

Por certo, não temos em vista as questões factuais relativas ao modo em que na história dos diferentes povos foram estabelecidas as instituições público-estatais, mas sim a questão da legitimidade, ou, para utilizar a terminologia jurídica, a questão da validade (i) dos processos de estabelecimento de tais instituições e (ii) do exercício dos poderes de Estado, uma vez consumada tal instituição.

Este foi um tema central do debate entre os grandes juristas normativistas e decisionistas na Alemanha dos anos 20, cujo conteúdo essencial pode ser restituído, ainda que esquematicamente, se lembrarmos os termos em que Hans Kelsen e Carl Schmitt teorizaram o assunto.

II

A posição de Kelsen se concentra e resume na tese de que o fundamento de uma norma só pode estar em outra norma. É o que se expressa cristalinamente na seguinte passagem da Teoria Pura do Direito:

Do fato de algo ser não pode seguir-se que algo deve ser; assim como do fato de algo dever ser se não pode seguir que algo é. O fundamento 
de validade de uma norma apenas pode ser a validade de uma outra norma (KELSEN 2002, p. 215).

Esta posição evidentemente clausura o espaço normativo. A admiti-la, será forçoso aceitar que, quanto à gênese, o sistema de normas não tem exterior, sendo absolutamente vão o esforço para ancorá-lo em realidades sociológicas, políticas ou institucionais que, de um modo ou de outro, em uma ou outra circunstância, factualmente o circunscrevam.

Quando enunciada com ânimo polêmico, essa tese vai a ponto de dizer que, quanto à validade, nem mesmo o comando divino, ainda que proferido diretamente pelo próprio Deus, pode ser admitido como fundado na autoridade de quem prescreve. É o que Kelsen sustenta mediante o argumento seguinte:

Na verdade, parece que se poderia fundamentar a validade de uma norma como o fato de ela ser posta por qualquer autoridade, por um ser humano ou supra-humano: assim acontece quando se fundamenta a validade dos Dez Mandamentos com o fato de Deus, Jeová, os ter dado no Monte Sinai; ou quando se diz que devemos amar nossos inimigos porque Jesus, o Filho de Deus, o ordenou no Sermão da Montanha. Em ambos os casos, porém, o fundamento de validade, não expresso mas pressuposto, não é o fato de Deus ou o filho de Deus ter posto uma determinada norma num certo tempo e lugar, mas uma norma: a norma segundo a qual devemos obedecer aos mandamentos de Seu Filho (KELSEN 2002, p. 215-216).

Evidentemente esta é uma formulação aguda e radical da tese normativista, a qual, convém insistir, tem seu ponto central na afirmação de que, em não havendo uma gênese possível do universo normativo, devemos reconhecer que a noção de dever ser é "um dado imediato de nossa consciência" (KELSEN 2002, p. 6).

Esta, aliás, a razão que leva Kelsen a sustentar - depois de reconhecer que o processo de regressão mediante o qual busca-se o fundamento de validade, de uma norma em outra norma, não pode prosseguir indefinidamente - que a última e mais elevada norma, a 
norma fundamental, não pode ser considerada como posta, devendo-se entender, antes, que ela é necessariamente pressuposta ${ }^{1}$.

\section{III}

Já as posições decisionistas se colocam em uma perspectiva antípoda a esta, considerando que é impossível conceber a ideia de um fechamento absoluto do universo normativo sobre si mesmo. Assim Carl Schmitt diz, por exemplo:

Juridicamente podemos encontrar o último fundamento jurídico de todas e quaisquer validades e valores de direito em um processo volitivo, uma decisão que enquanto tal cria o 'direito' e cuja 'força jurídica' não pode ser derivada da força jurídica de regras de decisão, pois mesmo uma decisão que não corresponde à regra cria direito (SCHMITT, 2001, p. 179).

E logo adiante Schmitt acrescenta:

A decisão soberana não é [...] explicada a partir de uma norma nem a partir de um ordenamento concreto, porque, muito pelo contrário, somente a decisão fundamenta para o decisionista tanto a norma quanto o ordenamento. A decisão soberana é o início absoluto, e o início (também no sentido de $\alpha \hat{\rho} \chi \eta ்$ não é outra coisa senão decisão soberana. Ela nasce de um nada normativo e de uma desordem concreta (SCHMITT, 2001, 182).

E Schmitt precisa ainda que a decisão fundadora não pode ser entendida simplesmente como um comando, mas que precisa ser entendida, antes, como um comando soberano sendo precisamente a força inconstrastada da vontade soberana que confere a suas iniciativas políticas

É o que se explica no texto seguinte: "Como já notamos, a norma que representa o fundamento de validade de uma outra norma é, em face desta, uma norma superior. Mas a indagação do fundamento de validade de uma norma não pode, tal como a investigação da causa de um fenômeno, perder-se no interminável. Tem que terminar numa norma que se pressupõe como a última e a mais elevada, ela tem que ser pressuposta, visto que não pode ser posta por uma autoridade, cuja competência teria de se fundar numa norma ainda mais elevada" (KELSEN, 2002, p. 217). 
inaugurais o caráter fundador de toda ordem jurídica possível. É o que se esclarece na passagem seguinte:

Para o jurista do tipo decisionista não é o comando enquanto comando, mas a autoridade ou soberania de uma decisão última, dada como comando, que constitui a fonte de todo e qualquer 'direito', isto é, de todas as normas e ordenamentos seguintes (SCHMITT, 2001, 179).

IV

A nitidez e o vigor conceitual dessas posições polares são indiscutíveis, mas é evidente que em cada uma delas há uma espécie de ponto limite que torna o espírito insatisfeito e que o faz oscilar, rebatidamente, entre as pontas desta alternativa exigente.

Porque não parece razoável conceber o universo das normas como blindado às injunções do mundo, como se a legitimidade dos sistemas normativos concretos não tivessem nada a ver com os processos reais de geração dos Estados e dos sistemas jurídicos. Por outro lado, a ideia básica que sustenta o ponto de vista normativista é a recusa de que possa haver trânsito dos fatos ao direito e tal ideia é, reconhecidamente, muito forte. No entanto, sempre se pode perguntar: por que precisamos aceitar a força prescritiva das normas? E mesmo que aceitemos a lição de Rousseau de que a força não gera nenhum direito e de que, a admiti-lo, segue-se que tão logo se possa desobedecer impunemente se poderá fazê-lo legitimamente (ROUSSEAU, 1964, p, 354355), sempre se poderá argumentar que submetermo-nos a obrigações prescritas por terceiros e dispormo-nos a obedecê-las mesmo quando não ameaçados diretamente de punição só é admissível sob condição de que tais normas sirvam a tais ou quais interesses, ou a tais ou quais fins e não simplesmente porque, imotivadamente, precisemos estruturar nossas ações em função de prescrições incondicionadas.

Além disso, como assinala Carl Schmitt, "a ideia do direito é incapaz de ela própria efetivar-se", sendo evidente que a existência de um ordenamento jurídico positivo dependerá de uma autoridade real que o estabeleça ou mantenha. É o que Schmitt diz, muito convincentemente, na passagem seguinte: 
Na realidade uma Constituição é válida quando emana de um poder (quer dizer: força ou autoridade) constituinte e é estabelecida por vontade dele. A palavra 'vontade' significa, em contraste com simples normas, uma magnitude do Ser, como origem de um dever-ser. A vontade se dá de um modo existencial: sua força ou autoridade reside em seu ser. Uma norma pode valer quando é justa; então a concatenação sistemática conduz ao direito natural e não à constituição positiva; ou bem uma norma vale porque está positivamente ordenada, quer dizer: em virtude de uma vontade existente. Uma norma nunca se estabelece por si mesma (isto é só um modo fantástico de falar) [...] (SCHMITT, 1981, p. 10).

O que é simplesmente reconhecer que os conjuntos normativos não vêm às sociedades caídos do céu, pois manifestamente não há, nem nunca houve, sistema algum de normas jurídicas que não tenha sido soberana e factualmente instituído e validado por uma determinada comunidade em um ou outro momento - na verdade em muitos momentos - de sua respectiva história. Mas também parece indiscutível, como querem os normativistas, que simplesmente a efetividade e a eficácia coercitiva e coativa de uma vontade política soberana não são fontes suficientes da validade do ordenamento jurídico ao qual derem sustentação.

Na verdade, como definitivamente estabelecido desde o Esclarecimento, homens livres e emancipados não têm porque submeter-se imotivadamente ao querer alheio, sob pena de reconduzirem-se voluntariamente a um estado de minoridade e de incapacidade moral. Além disso, é também evidente que, face ao desenho institucional e ao conteúdo das políticas implementadas pelo poder efetivamente existente, sempre poderá ocorrer que se lhe possa contestar a legitimidade, opondo-lhe argumentos de defesa da justiça e de proteção a direitos humanos fundamentais.

Seja como for, na linha de interesse que comanda este artigo, o principal não é propriamente avaliar os argumentos que podem ser levantados para defesa de uma ou de outra dessas posições contrapostas. O que importa aqui é, antes, destacar que no confronto entre normativistas e decisionistas se pode identificar uma espécie de 
antinomia do pensamento sobre a fundação do direito político, para valer-me da expressão utilizada no subtítulo do Contrato Social. Uma antinomia que, conquanto tenha encontrado uma expressão exemplarmente clara no confronto das posições de Kelsen e de Carl Schmitt, deve ser reconhecida, não apenas como anterior à polêmica entre esses autores, mas, na verdade, como constituindo $o$ problema subjacente à toda discussão teórica sobre o poder constituinte e sobre os atos de fundação constitucional.

Nesse sentido, creio que se pode sustentar que tal conflito, tal como as antinomias da razão pura e a da razão prática, motivou e foi objeto de uma iluminadora investigação kantiana (ainda que, obviamente, à diferença do que ocorreu com aquelas, Kant não a tenha desdobrado ex professo, nem lhe tenha dado um tratamento explícito e sistemático), a cuja lição, agora, é muito oportuno que atentemos.

\section{V}

Para avaliar a força heurística e resolutiva do que estamos propondo denominar - por certo, não sem risco de anacronismo - o tratamento kantiano da antinomia do direito político, o primeiro ponto a lembrar é que, para Kant, o contrato social, o pactum unionis civilis (pelo qual todos <omnes et singuli> abandonam no povo sua vontade exterior para reencontrá-la enquanto membros da república, isto é, de um povo consolidado como Estado), (KANT, 2003, p. 158; Ak, 6, p. 315) não só não pode ser tido como um $f \mathrm{tto}^{2}$, mas deve, muito diferentemente, ser considerado como uma "simples idéia da razão" (KANT 1988, p. 82-82; Ak, 8, p. 297).

Em segundo lugar, é preciso entender que se o contrato social é, assim, concebido como possuidor de um estatuto exclusivamente ideal, então é forçoso que se conceba a vontade geral - o que Kant denomina

2 Assim lê-se em Sobre a expressão corrente: isto pode ser correto na teoria, mas nada vale na prática: "Mas este contrato (chamado contractus originarius ou pactum sociale), enquanto coalizão de todas as vontades particulares e privadas em um povo... não se deve de modo algum pressupor... como um facto..." (KANT, 1988, p. 82-83; Ak, 8, p. 297). 
a vontade unificada e unificante do povo - como uma mera representação conceitual, cuja efetividade só poderá estar fora dela mesma, dependente da existência de um portador que se imponha como seu representante efetivo. Isto é o que Kant nos faz entender na passagem seguinte:

Os três poderes num Estado, procedentes do conceito de coisa pública em lato sentido (res publica latius dicta), são apenas as três relações da vontade unida do povo, que deriva a priori da razão. Constituem uma Idéia pura de um chefe de Estado, que possui realidade prática e objetiva. Mas este chefe de Estado (o soberano) é somente uma entidade-de-pensamento (para representar todo o povo) enquanto não há pessoa física para representar a suprema autoridade do Estado e efetivar essa idéia na vontade do povo (KANT, 2003, § 51, p. 182; $A k, 6$, p. 338).

O texto é claro, mas convém não entendê-lo de maneira demasiado trivial. Diz-se ali, por certo, que, por ser a vontade unida do povo apenas um conceito, ela permanecerá como um ente de razão enquanto não houver uma pessoa jurídica que represente o poder supremo do Estado. Mas Kant dá ainda o passo seguinte e sustenta, positivamente, que a república só se realizará na medida em que houver uma pessoa efetivamente existente que assuma empiricamente o poder supremo e que determine o exercício de seu império segundo a Idéia da vontade unida do povo (KANT, 2003, § 42, p. 151; Ak, 6, p. 306).

Se, nesta altura, evocarmos as posições polarizadas apresentadas acima, parece claro que Kant está a defender uma das teses centrais de Carl Schmitt e dos decisionistas: exatamente a que sustenta ser inconcebível que uma norma se estabeleça por si mesma.

Parece inegável, portanto, que há uma linha de afinidade entre as concepções kantiana e schmittiana da fundação constitucional e do poder constituinte. Na verdade, uma linha de ascendência, que, surpreendentemente, no que tange à compreensão do poder constituinte e da fundação do Estado, colocaria Kant mais perto de Schmitt do que de Kelsen. Esta convergência se mostra ainda mais claramente na conclusão do Apêndice à segunda edição da Metafísica dos Costumes. Ali, ao apresentar e responder a última das observações que Friedrich 
Bouterwek dera a público, um ano antes, no Jornal de Göttingen, quando da primeira edição da obra, Kant diz:

E finalmente, o autor da resenha fez a seguinte observação acerca das idéias que apresentei sob o título de Direito Público [...]: «Pelo que sabemos, nenhum filósofo admitiu até agora esta mais paradoxal de todas as proposições paradoxais: a proposição de que a mera idéia de soberania deveria constranger-me a obedecer como a meu senhor quem quer que se haja estabelecido $\mathrm{como} \mathrm{tal}^{3}$, sem que eu lhe perguntasse quem lhe deu o direito de comandar-me. Não há diferença entre dizer que alguém deve reconhecer a soberania e a autoridade suprema e dizer que alguém deve considerar priori como seu senhor esta ou aquela pessoa, cuja existência não é dada sequer a priori? (Id., p. 169 e seguintes; $A k, 6$, 356 e seguintes).

Sublinhe-se, antes de mais, que Kant admite expressamente o pensamento culminativamente paradoxal que lhe é atribuído, o que, convenhamos, não é pouco admitir! ${ }^{4}$

Ora, não há como deixar de ver que essa posição se aproxima da tese de Schmitt, consoante a qual "uma Constituição é válida quando emana de um poder (quer dizer: força ou autoridade) constituinte e é estabelecida por vontade dele"! Essa aproximação se confirma uma vez mais quando Kant ocupa-se de precisar as razões de escândalo de seu crítico e diz sem qualquer constrangimento:

Mas o que parece chocar a razão do autor da resenha não é apenas esse princípio, que transforma um fato real (o da tomada do poder ${ }^{5}$ ) na condição e base para um direito, mas também que a mera idéia de soberania sobre um povo me constrange, como membro pertencente a este povo, a obedecer sem previamente investigar o direito que é reivindicado (KANT, 2003, p. 214; Ak, 6, 371) ${ }^{6}$.

Edson Bini repete aqui como meu senhor. Cf. KANT, 2003, p. 213.

4 Sustentando, porém, que, não por isso, se o poderá acusar de heterodoxia (KANT, 2003, 213-214; Ak, 6, 371).

5 Edson Bini diz: 0 apoderamento.

6 É manifesto, portanto, que Kant reconhece a Bouterwek dois motivos de escândalo, a saber: a ousadia de colocar um fato como fundamento do direito; e a tese de que uma simples ideia possa implicar uma obrigação externa (KANT, 2003, p. 214; $A k, 6,371)$. 
Como se sabe, Kant não recuará diante dessas duas formulações admitidamente paradoxais. Antes, cuidará de mostrar como é indispensável que se admita a ambas e se efetivamente se quiser entender o fundamento do direito público ${ }^{7}$.

Para fechar mais finamente a análise do ponto, convém ainda chamar atenção para o fato de que Bouterwek distingue (i) o imperativo de reconhecimento do poder soberano do (ii) imperativo de reconhecimento de um soberano. O que é dizer que Bouterwek lê a Kant como sustentando que a obrigatoriedade da obediência incondicional ao poder soberano deve ser entendida não apenas de dicto, mas de re. Ou, como nos é dito na conclusão do Apêndice: devemos tomar por senhor àquele que tiver de fato poder suficiente para impor-se aos demais ${ }^{8}$.

\section{VI}

Tal como insinuado até aqui, pareceria, portanto, que o pensamento de Kant seria uma versão avant la lettre da tese fundamental de Schmitt e que suas análises, antes que conterem os elementos para uma eventual superação da antinomia relativa à fundação do direito político, apenas reforçaria uma das posições contrapostas.

No entanto, não é essa a posição de Kant e nos próprios textos recém citados é possível perceber os elementos que arredam a posição kantiana do decisionismo estrito.

7 É verdade, no entanto, que Kant acrescenta imediatamente que se deve ter a mais paradoxal das proposições paradoxais como um princípio fundamental da Doutrina do Direito. Uma proposição, podemos ainda acrescentar, que, interpretada sistematicamente, vem a revelar-se como o imperativo categórico da razão prática em seu uso jurídico.

8 A esse terceiro aspecto paradoxal da posição kantiana, é ainda preciso agregar um quarto, contido na tese de que 0 imperativo categórico jurídico é analítico, eis que, pelo menos em tese, nada poderia ser menos paradoxal do que uma verdade analítica (no Apêndice que estamos a comentar esta tese está implicada na passagem seguinte: "Permitir qualquer resistência a esse poder absoluto (resistência que limitaria esse poder supremo) seria contraditório, pois nesse caso esse poder supremo (que é resistivel) não seria o poder supremo legal que determina em primeira instância o que deve ser publicamente direito ou não.)" (KANT, 2003, p. 215; Ak, 6, 373). Já no capítulo X da Introdução à Doutrina da Virtude, a afirmação do caráter analítico do imperativo categórico jurídico é expressa explicitamente. 0 título do capítulo [...] diz, com efeito: "0 princípio supremo da Doutrina do Direito era analítico, o da doutrina da virtude é sintético" (KANT, 2003, 239; Ak 6, 396).

Rev. Filos., Aurora, Curitiba, v. 29, n. 47, p. 503-521, maio/ago. 2017 
Para destacar essa diferença convém que consideremos, primeiramente, a tese de que o fundamento do direito é um fato, nomeadamente o fato da tomada do poder por alguém. O necessário aqui é distinguir, porque, muito embora Kant efetivamente sustente que, originariamente, a constituição civil deriva de um fato - do fato da tomada do poder por um sujeito real que ao afirmar seu poder incontrastado funda o direito público (KANT, 2003, p. 215; Ak, 6. p. 372) - tal fato só se torna fundamento do direito, na medida em que, previamente a ele, a priori, na verdade, há um imperativo categórico da razão prática em seu uso jurídico que nos comanda obedecer incondicionalmente à autoridade que tiver poder sobre nós. É o que se depreende dos textos seguintes:

A idéia de uma constituição civil como tal, que é também um comando absoluto que a razão prática, julgando conceitos jurídicos, confere a todo povo, é sagrada e irresistível. [...] O comando «Obedece a autoridade que detém poder sobre ti» não indaga como essa autoridade chegou a deter esse poder [...] pois a autoridade que já existe, sob a qual tu vives, já está de posse do poder legislativo, e embora possas efetivamente raciocinar publicamente acerca de sua legislação, não podes erguer-te na qualidade de um legislador oponente (KANT, 2003, p. 215; Ak, 6, p. 372).

Repare-se que o pensamento de Kant é singular não por admitir que certos fatos gerarão certos de direitos, mas por combinar esse reconhecimento com o enunciado de uma norma meta-positiva que confere a um certo fato - o fato do exercício de um poder factualmente inabalado - a legitimidade necessária para constituir-se - obviamente não em origem de comandos impostos exclusivamente pela força - mas em fonte e padrão originários e validadores do direito positivo.

A previsão por parte de uma norma de que fatos gerem novos direitos é, por certo, trivial. Este é o caso, para dar um exemplo qualquer, das mortes, que têm como efeitos gerarem o direito à herança por parte de quem detiver com os finados as relações de parentesco legalmente pertinentes. No entanto, com relação aos atos e processos de fundação do Estado, a norma que antecede ao fato não é, como no 
caso de dispositivos normativos integrados a uma ordem jurídica já estabelecida, posta positivamente, senão que, consoante a lição de Kant, tem o estatuto singularíssimo de um comando a priori da razão prática.

Deste ponto de vista, portanto, contrariamente ao que vínhamos sugerindo, é evidente que Kant aceita o princípio geral do normativismo, para o qual a validade de uma norma só pode estar fundada em outra norma9.

\section{VII}

Nesta altura cabe assinalar que a análise que acaba de ser resumida não dissolve o paradoxo apontado por Bouterwerk, antes o reitera, o que, aliás, é admitido expressamente por Kant, pois, não obstante a existência do imperativo categórico da razão jurídica, não deixa de ser verdadeiro que:

A submissão incondicional da vontade do povo (a qual em si mesma não é unida, sendo, portanto, sem lei) a uma vontade soberana (que tudo une por meio de uma lei) é um fato que só pode ter início mediante a assunção [Bemächtigung] do poder supremo [obersten Gewalt], pela qual é inauguralmente estabelecido o direito público (KANT, 2003, p. 215; Ak, 6, p. 372, tradução modificada).

O que caberia perguntar agora é se não é justamente o paradoxo de Kant que abre caminho para superação da antinomia frente a qual parece inelutavelmente malograr o pensamento sobre a fundação do direito político.

A propósito, assinale-se que, muito embora haja uma compatibilidade essencial entre (i) o princípio normativista de que somente uma norma pode servir de fundamento para a validade de outra norma e (ii) a tese kantiana de que, como fundamento de toda ordem política, se encontra o comando absoluto da razão em seu uso jurídico (de que aceitemos

9 Acrescente-se ainda, na mesma linha, que, nos termos mais estritos do criticismo, 0 que torna categórico 0 imperativo "Obedecei à autoridade que detém poder sobre ti» - isto é: o que "torna necessária" a ação "não éa representação de algum fim [... mas a simples representação dessa própria ação (sua forma)" (KANT 2003, p. 65; Ak, 6, 222). 
como autoridade legitimamente constituída a quem quer que exerça o poder soberanamente), não é menos certo que há entre as posições kelseniana e kantiana uma diferença importante, pois a norma fundamental do direito político é pensada por Kant como sendo necessariamente posta e não simplesmente pressuposta, ainda que tal posição seja de caráter meta-positivo, seu sujeito sendo a razão prática.

Na verdade, Kelsen toma tal diferença como evidência de que o pensamento do século XVIII ainda não alcançara a plena maturidade, a formulação de Kant devendo ser considerada como mais um dentre os muitos casos do tipo metafísico de "normas de justiça", por oposição ao tipo racional e científico. Com efeito, no ensaio Justiça e Direito Natural, lê-se o seguinte:

As normas de justiça do tipo denominado aqui racional por oposição ao tipo «metafísico» apresentam as características seguintes: elas não postulam nenhuma crença na existência de uma instância transcendente; pode-se representá-las como estatuídas por atos humanos realizados no mundo da experiência e elas podem ser compreendidas pela razão humana, isto é: apreendidas de maneira racional. Mas isso não significa que essas normas possam ser criadas pela razão humana enquanto «razão prática», ou descobertas no seio dessa razão (KELSEN, 1959, p. 13-14).

No entanto, se poderia retrucar que a tese kelseniana de que a norma fundamental não pode ser posta, mas, antes, tem que ser, pressuposta, sob pena de que "o processo de justificação normativa não tivesse fim", daí seguindo-se que "a questão de saber como devemos agir restaria sem resposta possível" (KELSEN, 1959, p. 11), é tão metafísica, para utilizar o mesmo jargão empregado por Kelsen nessa passagem, quanto à tese kantiana, pois é evidente que frente a tal supostamente indesejada conclusão, o cético moral e jurídico poderia muito bem dizer: e daí? o que importa que fiquemos sem resposta à "questão de saber como devemos agir"?

Muito mais relevante do que essa contra objeção hipotética é, no entanto, a explicitação do caráter racional do imperativo absoluto 
contido, como diz Kant, já na própria ideia de constituição civil, e é sobre isso que devemos concentrar a atenção.

Com efeito, segundo a análise de Kant, o imperativo que nos ordena aceitar como legítimo o poder exercido por quem for capaz de fazê-lo soberanamente, e válidas as normas por ele exaradas, radica na evidência racional de que, na ausência de um poder soberano, o convívio humano se vê entregue, inapelavelmente, ao conflito e as intermináveis disputas entre os particulares. É o que explica com muita clareza a passagem seguinte:

Do direito privado no estado de natureza procede o postulado do direito público: quando não podes te furtar a viver lado a lado com todos os outros, deves abandonar o estado de natureza e ingressar com eles num estado jurídico [...]. O fundamento deste postulado pode ser desenvolvido analiticamente a partir do conceito de direito nas relações externas, no confronto com a violência (violentia). Ninguém é obrigado a abster-se de violar a posse alheia se o outro não lhe proporcionar igual certeza de que observará a mesma abstenção em relação a ele. [...] E não é necessário esperar por hostilidade real; está-se autorizado a usar a coerção contra alguém que, por sua natureza, já o ameaça com coerção." (KANT, 2003, § 42, p. 152; Ak, 6, p. 307) ${ }^{10}$.

É por isso que Kant dirá em seguida que:

[...] a menos que se queira renunciar a quaisquer conceitos de direito, a primeira coisa [...] a resolver é estabelecer o princípio segundo o qual é preciso abandonar o estado de natureza, no qual cada um segue seu próprio critério, e unir-se com todos os outros (com os quais a interação é inevitável), submeter-se a uma coação legal externa pública e, assim, ingressar numa condição na qual o que tem que ser reconhecido como

${ }^{10}$ Logo adiante Kant retomará o ponto dizendo: "Não é a partir da experiência que aprendemos sobre a máxima de violência dos seres humanos e de sua malevolente tendência para se atacarem mutuamente antes de aparecer a legislação externa dotada de poder. Não é, portanto, um fato que torna necessária a coerção através da lei pública. Pelo contrário, por melhores predispostos e acatadores da lei que pudessem ser os homens, ainda assim está assentado a priori na idéia racional de uma tal condição (aquela que não é jurídica) que antes de uma condição legal pública ser estabelecida, indivíduos humanos, povos e Estados jamais podem estar seguros contra a violência recíproca, uma vez que cada um detém seu próprio direito de fazer o que parece certo e bom para si e não depender da opinião alheia com respeito a isso" (KANT, 2003, § 44, p. 154; Ak, $6,312)$. 
a ela pertinente é determinado pela lei e lhe é atribuído por um poder adequado (não o que lhe é próprio, mas sim um poder externo); em síntese: deve-se acima de tudo o mais, ingressar numa condição civil (KANT, 2003, § 44, p. 154; Ak, 6, 312).

Vê-se, portanto, que o fundamento racional dessa prescrição é uma espécie de dependência necessária do sistema normativo externo, não do estado contingente das relações entre os homens, mas de certas condições estruturais do convívio humano que se expressam nos termos da interação privada quando desenrolada na ausência de um poder coercitivo externo. Em tal situação, os homens necessariamente vivem em um regime de insegurança pessoal e jurídica do qual a razão lhes prescreve evadir-se.

Isto quer dizer que o que Kant denomina, no $\S 42$ da Metafísica dos Costumes, de postulado do direito público, consoante o qual nos é prescrito abandonar o estado de natureza e ingressar em um estado jurídi$\mathrm{co}$, ainda que se constitua em uma norma fundamental antecedente à fundação do direito positivo, difere profundamente da norma fundamental kelseniana, cuja justificativa é inteiramente alheia às condições materiais que tornam racionalmente desejável e, portanto, normativamente obrigatório, o ingresso no estado jurídico e que, muito diferentemente, se explica, exclusivamente, em função de um requisito formal de consistência para os ordenamentos jurídicos positivos.

Percebe-se, assim, que Kant, embora, tal como Kelsen, ponha a fundamento do direito público uma norma fundamental, propõe para esta uma justificativa enquadrada nas premissas do contratualismo moderno, permanecendo inteiramente alheio, portanto, a uma posição formalista como a que viria posteriormente a ser formulada pelo normativismo kelseniano ${ }^{11}$.

11 Assinale-se ainda, muito em passant, que a prescrição racional de abandonar o estado de natureza não pode ser entendida como um cálculo a ser feito individualmente por cada indivíduo em função de seu próprio interesse, à maneira de Hobbes, mas há de ser entendida como um imperativo categórico, cuja justificativa pode e deve ser entendida como derivada descontextualizadamente, sem dependência da avaliação das posições particulares em que se encontram cada um de seus destinatários. 
De outra parte, na medida em que não se faz ilusões sobre as condições de formação real dos Estados e das instituições de direito público, Kant sustenta as posições paradoxais vistas acima, notadamente a tese de que é obrigatório aceitar como autoridade legítima a quem exitosamente empalmar o poder em uma dada comunidade e nela afirmar-se como autoridade soberana.

O que mais importa observar, porém, é que Kant não aceita separar as prescrições normativas externas, próprias do direito, do elemento coativo que, segundo sua doutrina, lhe é igualmente inerente e essencial. É o que nos é dito com muita clareza no texto seguinte:

[...] o direito não deveria ser concebido como constituído de dois elementos, a saber, uma obrigação de acordo com uma lei e uma competência de quem, por meio de sua escolha, submete outrem à obrigação para coagi-lo a cumpri-la. [...] Direito e competência de empregar coerção, portanto, significam uma e única coisa [ênfase minha, jc]. (KANT, 2003, p. 78; $A k, 6$, p. 232).

Combinada esta tese com o princípio de que, a "submissão incondicional da vontade do povo a uma vontade soberana é um fato que só pode ter início mediante a assunção do poder supremo, pela qual é inauguralmente estabelecido o direito público"12, percebe-se a razão pela qual sugerimos acima que a posição de Kant se encontraria mais próxima de Carl Schmitt do que de Kelsen.

\section{VIII}

Para concluir, o que cabe perguntar, porém, é se esses diferentes aspectos do pensamento kantiano, longe de serem uma solução da antinomia do pensamento sobre a fundação do direito político, não devem ser considerados como uma espécie de contradição interna do pensamento de Kant, que não se aperceberia de seu caráter intrinsecamente aporético.

12 Edson Bini diz agarrando-se a autoridade suprema. (Cf., KANT, 2003, p. 215; Ak, 6, p. 372). 
Kant, por certo, sustenta posições congruentes com o normativismo ao sustentar que a validade dos atos de fundação constitucional assenta em um imperativo da razão prática. Mas, por outro lado, como vimos repetidamente, ao sustentar que os sistemas normativos realmente existentes se instauram a partir do fato de que alguém se arvora exitosamente em autoridade suprema e, assim, estabelece o direito público, antecipa uma tese que será essencial para os decisionistas.

À luz desses elementos, creio, no entanto, que no caso do que estamos propondo denominar a antinomia do direito público deve-se admitir que as posições polares sejam ambas verdadeiras. Evidentemente, se esse for o caso, então a antinomia da razão jurídica precisaria ter uma estrutura análoga a das antinomias dinâmicas analisadas na Crítica da Razão Pura, cabendo também com relação a ela distinguir o plano fenomenal do plano das relações numênicas.

Ora, creio que é exatamente isso que Kant quer sugerir quando diz, ao mesmo tempo, (i) que a representação de uma constituição perfeitamente jurídica é uma Ideia e que seu objeto é da ordem das coisas em si e (ii) que a existência de um povo unido juridicamente sob uma vontade soberana, embora dada somente no terreno fenomênico, deve ser considerada como instanciando efetivamente a Idéia de uma constituição jurídica. É o que nos é explicado na passagem seguinte:

Todo ato real (fato) é um objeto em aparência (para os sentidos). Por outro lado, o que pode ser representado somente pela razão pura e tem que ser computado entre as idéias, para as quais nenhum objeto dado na experiência pode ser adequado - e uma constituição perfeitamente jurídica entre seres humanos pertence a esse tipo - é a coisa em si. Se então existe um povo unido por leis sob uma autoridade, é dado como objeto da experiência em conformidade com a idéia da unidade de um povo como tal sob uma poderosa vontade suprema, ainda que seja realmente dado somente na aparência, isto é, uma constituição jurídica no sentido geral do termo, existe (KANT, 2003, p. 214; Ak, 6, p. 371-2).

Para bem compreender essa análise é preciso, porém, primeiramente, aceitar as teses kantianas expostas há pouco de que (i) direito e competência de empregar coerção significam uma e única coisa e de que (ii) 
não pode haver direito e coerção públicos sem que se produza a tomada do poder por alguém, isto é, como defende Carl Schmitt, sem a decisão soberana, que é o início absoluto de toda ordem político-jurídica efetiva.

O sentido mais profundo dessa análise kantiana - isto é, da afirmação simultânea dessas duas teses - só se deixa revelar, no entanto, se admitirmos que aqui, contrariamente ao que se diz na refutação do argumento ontológico na Crítica da Razão Pura (A 600/B 628), se agregarmos a um conceito inteiramente defectivo do ponto de vista do direito público - notadamente o de um poder despótico - seu caráter factual, vale dizer, sua existência, teremos agregado a ele uma perfeição jurídica - na verdade, ter-lhe-emos acrescentado $a$ perfeição jurídica básica - , posto que estabelecer uma autoridade que se imponha a uma multidão é realizar a Ideia de unidade em geral sob uma autoridade suprema e satisfazer o postulado fundamental do direito público.

O que é sustentar, não apenas que a ideia do soberano contém a existência como uma de suas notas, mas também que o puro fato do poder político é uma nota essencial do conceito de Estado, isto é: a condição real - não a condição simplesmente pensada - de unificação de uma multidão de homens sob uma autoridade comum.

\section{Referências}

KANT, I. Sobre a expressão corrente: isto pode ser correto na teoria, mas nada vale na prática. Trad. A. Morão. In: KANT, I. A Paz Perpétua e Outros Opúsculos. Lisboa: Edições 70, 1988.

KANT, I. Crítica da Razão Pura. Trad. Manuela Pinto dos Santos e Alexandre Fradique Morujão. Lisboa: Fundação Calouste Gulbenkian, 1989.

KANT, I. A Metafísica dos Costumes. Trad. Edson Bini. São Paulo: DIPRO, 2003.

KELSEN, H. Justice et Droit Naturel. Trad. Étienne Mazingue. In: KELSEN el alter. Annales de Philosophie Politique III, Le Droit naturel. Paris: PUF, 1959. 
KELSEN, H. Teoria Pura do Direito. Trad. João Baptista Machado. São Paulo: Martins Fontes, 2002.

ROUSSEAU, J.-J. Du Contrat Social. In: Oeuvres Complètes (tomo III). Paris: Gallimard, 1964.

SCHMITT, C. Sobre os três tipos de pensamento jurídico. Trad. Peter Naumann. In: MACEDO Jr., R. P. Carl Schmitt e a fundamentação do direito. São Paulo: Max Limonad, 2001.

SCHMITT, C. Teoria de la Constitución. Trad. Francisco Ayala. México: Editora Nacional, 1981.

Recebido: 10/06/2017

Received: 06/10/2017

Aprovado: $17 / 07 / 2017$

Approved: 07/17/2017 